\title{
PERANCANGAN APLIKASI PELAYANAN SURAT UNTUK MENINGKATKAN KINERJA KANTOR DESA
}

\author{
Wiyana $^{1}$, Surya Ade Saputera ${ }^{2}$, Andilala ${ }^{3}$ Khairullah $^{4}$ \\ 1,2,3 Universitas Muhammadiyah Bengkulu \\ Jl. Bali Po. Box 118 kota Bengkulu \\ ${ }^{1}$ wiyanajunia20@gmail.com, ${ }^{2}$ adesurya2012@gmail.com , \\ 33andilala@umb.ac.id, ${ }^{4}$ khairullah@umb.ac.id
}

\begin{abstract}
Correspondence services in the village are still not processed properly. To improve the effectiveness and efficiency in the creation of correspondence it is necessary to create a new system that is expected to help complete the tasks of village office staff managing population administration data. The method used in this research is RAD (Rapid Application Development). The system is built with the XAMPP tool that can test applications without requiring an internet connection, PHP programming language, and MySQL database. The result of this application is that it can help facilitate the process of service activities of village-level population letters, facilitate the collection of data of villagers, based on blackbox testing of each test criteria in accordance with the expected results. It is expected that this application is always up to date so that it follows the development of smartphone-based technology.
\end{abstract}

Keywords: Application, Service, Letter, Village.

Abstrak - Pelayanan surat menyurat di desa masih belum diolah dengan baik. Untuk meningkatkan efektivitas dan keefisiensi dalam pembuatan surat menyurat perlu diciptakan sistem baru yang diharapkan akan membantu menyelesaikan tugas-tugas staf kantor desa mengelola data administrasi kependudukan. Metode yang digunakan dalam penelitian ini adalah RAD (Rapid Application Development). Sistem ini dibuat dengan tool XAMPP yang dapat menguji aplikasi tanpa memerlukan koneksi internet, bahasa pemrograman PHP,dan basis data MySQL. Hasil dari aplikasi ini adalah dapat membantu mempermudah dalam proses kegiatan pelayanan surat-surat kependudukan tingkat desa, memperlancar pengumpulan data penduduk desa, berdasarkan pengujian blackbox testing setiap kriteria pengujian sesuai dengan hasil yang diharapkan. Diharapkan aplikasi ini selalu up to date sehingga mengikuti perkembangan teknologi berbasis smartphone.

Kata Kunci :Aplikasi, Pelayanan, Surat, Desa.

\section{Pendahuluan}

A. Latar Belakang

Pelayanan merupakan suatu proses, proses tersebut menghasilkan suatu produk yang berupa pelayanan, yang kemudian diberikan kepada pelanggan. Pelayanan yang baik akan memberikan dampak yang baik pula dari pelanggan berupa kepuasan pelanggan. Proses pelayanan pada dasarnya setiap manusia membutuhkan pelayanan, bahkan secara ekstrim dapat dikatakan bahwa pelayanan tidak dapat dipisahkan dengan kehidupan manusia. Membicarakan pelayanan berarti, membicarakan suatu proses kegiatan yang konotasinya lebih kepada hal yang abstrak (intangible) [1]. Pelayanan surat merupakan salah satu pelayanan administrasi yang ada di Desa. Dalam rangka membangun kualitas kinerja pemerintah yang efektif dan efisien diperlukan waktu untuk memikirkan bagaimana mencapai kesatuan kerjasama sehingga mampu meningkatkan kepercayaan masyarakat.[2].
Pelayanan surat merupakan bagian dari kualitas kinerja pemerintah desa, dengan pelayanan surat yang efektif dan efisien mampu meningkatkan kepuasan masyarakat terhadap desa, dengan ada nya pelayanan surat yang tersistematis mampu meningkatkan kinerja bagi kantor desa dalam melayani masyarakat.

Pemerintah Desa adalah Kepala Desa atau yang disebut dengan nama lain, dibantu perangkat Desa sebagai unsur penyelenggara pemerintahan desa. Pemeritah desa memberikan pelayanan kepada baik kepada warga desa, maupun pelayanan ke atas seperti kelurahan atau kecamatan. Pelayanan desa misalnya membuat surat menyurat. Pelayanan surat memberikan surat keterangan administrasi kependudukan kepada warga yang membutuhkan surat keterangan administrasi, sepert surat keterangan usaha, Surat keterangan Kelahiran, Surat Keterangan kematian, surat domisili,surat keterangan tidak mampu dan lain sebagainya. 
Desa Tebat Tenong Dalam merupakan salah satu desa yang terletak di daerah kecamatan Bermani Ulu, kabupaten Rejang Lebong, provinsi Bengkulu. Proses pelayanan surat di desa Tebat Tenong Dalam masih menggunakan cara manual yaitu pelayanan surat menyurat masih menggunakan program pengolah kata (Microsoft word). Dalam pengarsipannya staf desa menggunakan buku untuk mendata surat yang dikeluarkan. Dalam pembuatan surat, staf kantor desa harus memasukkan data pemohon lebih rinci. Staf desa sering melakukan kesalahan dalam memasukkan data penduduk yang mengajukan surat serta kesalahan tulisan dalam mengetik keterangan surat. Kurang telitinya staf desa tersebut sering membuat pemohon yang mengajukan surat kembali datang ke kantor desa untuk memperbaiki kesalahan surat.

Hal ini menjadi kendala dalam pelayanan kantor desa Tebat Tenong Dalam. Untuk meningkatkan efektivitas dan keefisiensi dalam pembuatan surat menyurat pada Desa Tebat Tenong Dalam maka perlu diciptakan langkahlangkah penerapan sistem baru yang diharapkan akan membantu menyelesaikan tugas-tugas staf kantor desa yang berkaitan dengan data kependudukan.

\section{Tinjauan Pustaka}

a. Aplikasi

Aplikasi berasal dari kata application yang artinya penerapan, lamaran, penggunaan. Secara istilah aplikasi adalah program siap pakai yang dibuat untuk melaksanakan suatu fungsi bagi pengguna atau aplikasi yang lain dan dapat digunakan oleh sasaran yang dituju. Aplikasi adalah perangkat lunak yang digunakan untuk tujuan tertentu, seperti mengolah dokumen, mengatur Windows dan permainan (game), dan sebagainya. aplikasi merupakan perangkat lunak yang digunakan untuk tujuan tertentu disusun sedemikian rupa sehingga komputer dapat menghasilkan input menjadi output.

b. Pelayanan

Pada dasarnya setiap manusia membutuhkan pelayanan, bahkan secara ekstrim dapat dikatakan bahwa pelayanan tidak dapat dipisahkan dengan kehidupan manusia. Membicarakan pelayanan berarti, membicarakan suatu proses kegiatan yang konotasinya lebih kepada hal yang abstrak (intangible) [1].

Pemenuhan kebutuhan pelayanan diatur dalam perundang-undangan. Kebutuhan pelayanan atas barang, jasa, atau pelayanan administratif disediakan oleh penyelenggara pelayanan publik ( UUD RI, 2009). Merupakan kewajiban negara dan amanat UUD RI, setiap warga negara dan penduduk mendapatkan pelayanan untuk kebutuhan dasar dan haknya [4].

c. Surat
Surat merupakan helai kertas dalam bentuk maupun dalam wujud apapun yang berisi keterangan-keterangan tertulis untuk disampaikan kepada pihak lain yang membutuhkan. Boleh juga dikatakan surat ialah persyaratan secara tertulis, untuk menyampaikan suatu informasi atau keterangan dari satu pihak ke pihak lain [5].

Dapat dikemukakan bahwa, surat adalah sehelai kertas bertulis atau lebih yang memuat suatu bahan komunikasi berupa pemberitahuan, permohonan, undangan dan lain-lain. Yang disampaikan seorang kepada orang atau pihak lain, baik atas nama pribadi maupun karena kedudukannya dalam suatu organisasi, instansi atau perusahaan.

d. Desa

Desa adalah desa dan desa adat atau yang disebut dengan nama lain, selanjutnya disebut Desa, adalah kesatuan masyarakat hukum yang memiliki wilayah yang berwenang untuk mengatur dan mengurus urusan pemerintahan, kepentingan masyarakat, berdasarkan prakarsa masyarakat, hak asal-usul dan/atau hak tradisional yang diakui dan dihormati dalam sistem pemerintahan Negara Kesatuan Republik Indonesia [6].

\section{III.Metodologi Penelitian}

A. Metode Pengembangan Sistem

Metode yang digunakan dalam penelitian ini adalah RAD (Rapid Application Development). Metode RAD merupakan pendekatan berorientasi objek untuk menghasilkan sebuah sistem dengan sasaran utama mempersingkat waktu pengerjaan aplikasi dan proses agar sesegera mungkin memerdayakan sistem perangkat lunak tersebut secara tepat dan cepat.

Metode ini sangat mementingkan keterlibatan pengguna dalam proses analisis dan perancangannya, dan dengan demikian dapat memenuhi kebutuhan pengguna dengan baik dan secara nyata akan dapat meningkatkan tingkat kepuasan pengguna sistem [7].

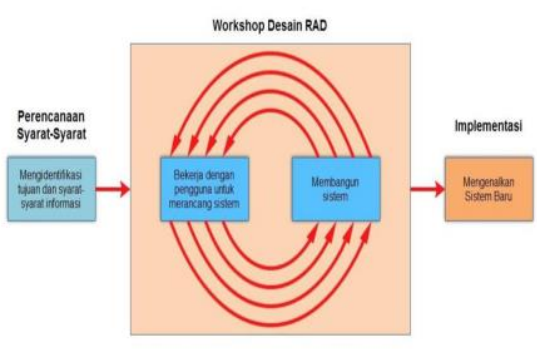

Gbr 1 Model Pengembangan RAD

B. Analisa Sistem Lama

Pada sistem lama pelayanan surat desa di Kantor Desa Tebat Tenong Dalam masih bersifat manual yaitu menggunakan Microsoft Word sebagai pembuatan surat. Sehingga pihak instansi desa membutuhkan waktu yang lama pada saat 
masyarakat akan mengajukan surat karena keterbatasan dalam mengolah surat.

Didalam sistem lama tersebut juga masih banyak kekurangan dan kelemahannya. Adapun kelemahannya adalah sebagai berikut:

a) Data yang dihasilkan belum akurat, sehingga dibutuhkan ketelitian lebih dari staf desa.

b) Proses rekapitulasi surat keluar masih menggunakan pencatatan di buku.

C. Analisa Sistem Baru

Analisa sistem yang akan penulis lakukan yaitu akan melakukan analisa sistem baru. Sistem baru ini akan dirancang dengan menggunakan bahasa pemrograman PHP serta berbasis desktop. Program ini nantinya akan memberikan solusi terbaik bagi pengguna komputer dalam proses pelayanan surat terutama pada saat pengisian data yang dianggap penting misalnya pengisian nama, tanggal lahir dan lain-lain. Program ini akan melakukan proses dengan cepat sehingga dalam pengisian data penduduk dapat dilakukan dengan cepat dan akurat.

D. Perancangan Sistem

1. Diagram Konteks

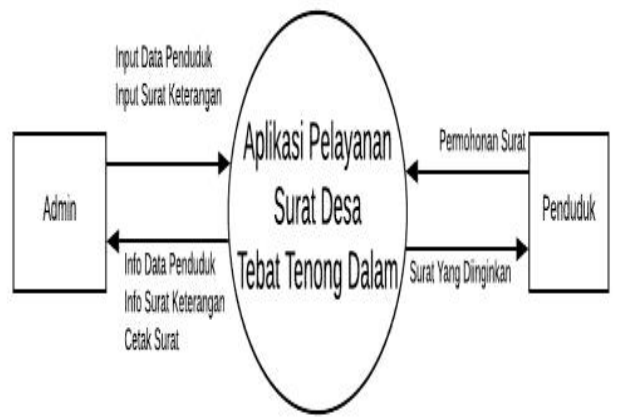

Gbr 2. Diagram Konteks

2. Data Flow Diagram Level 0

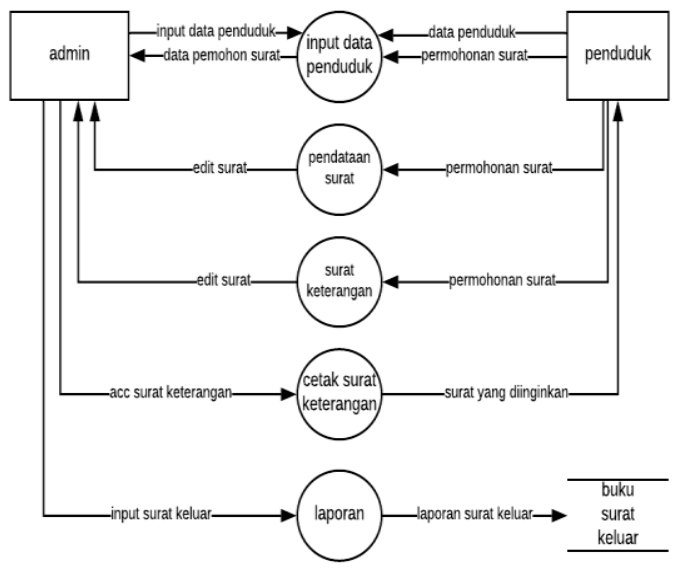

3. Data Flow Diagram Level 1 Proses 1

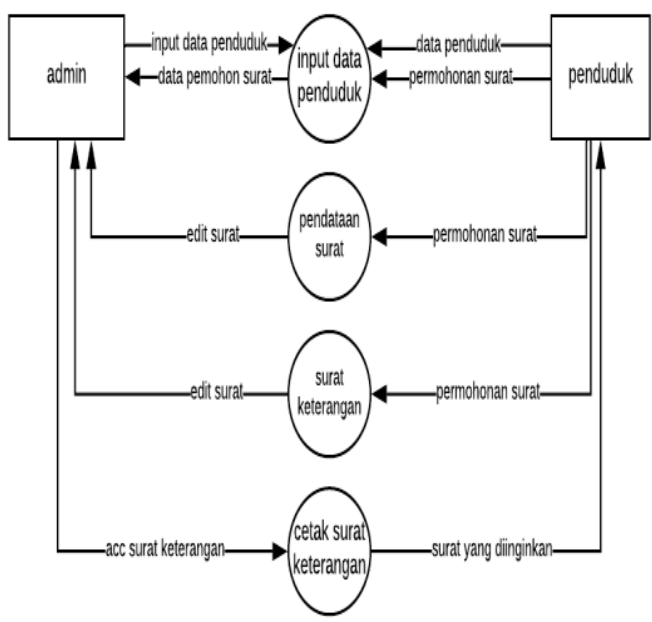

Gbr 4. Diagram Level 1 Proses 1

4. Data Flow Diagram Level 1 Proses 2

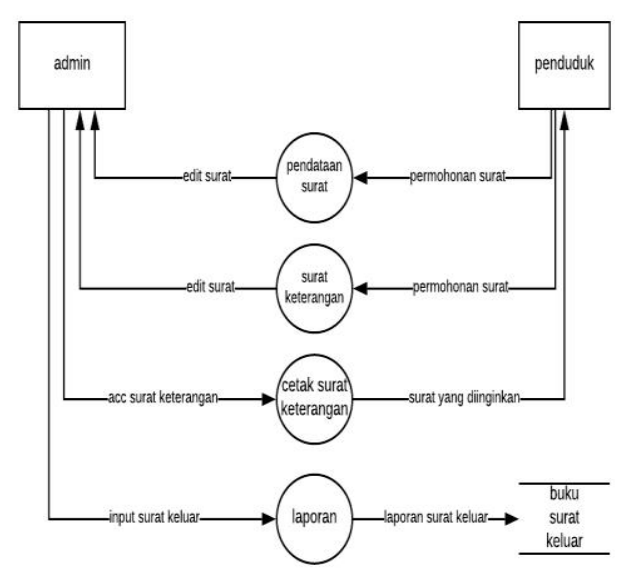

Gbr 5. Diagram Level 1 Proses 2

E. Entity Relationship Diagram (ERD)

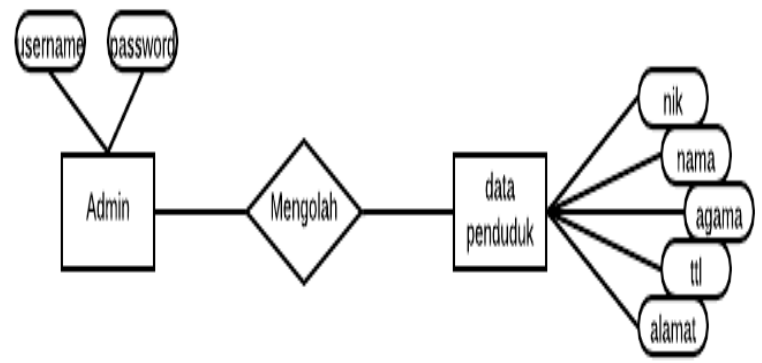

Gbr 6 Gambar ERD

Gbr 3. Diagram Level 0 
F. Perancangan Database

Rancangan Tabel 1. Admin

\begin{tabular}{|c|c|c|c|}
\hline No & $\begin{array}{c}\text { Nama } \\
\text { Field }\end{array}$ & $\begin{array}{c}\text { Tipe } \\
\text { Data }\end{array}$ & Keterangan \\
\hline 1 & username & varchar & $\begin{array}{c}\text { nomor identitas } \\
\text { admin }\end{array}$ \\
\hline 2 & password & varchar & password admin \\
\hline
\end{tabular}

Rancangan Tabel 2. Penduduk

\begin{tabular}{|c|c|c|c|}
\hline No & Nama Field & Tipe data & Keterangan \\
\hline 1 & id & integer & Nomor \\
\hline 2 & nik & varchar & $\begin{array}{c}\text { Nomor induk } \\
\text { keluarga }\end{array}$ \\
\hline 3 & nama & varchar & Nama penduduk \\
\hline 4 & agama & varchar & Identitas agama \\
\hline 5 & ttl & varchar & Tempat lahir \\
\hline 6 & alamat & text & Alamat penduduk \\
\hline
\end{tabular}

\section{IV.Hasil dan Pembahasan}

\section{A. Hasil}

Adapun hasil penelitian Aplikasi Pelayanan Surat ini, adalah sebagai berikut :

1. Untuk memperlancar pengumpulan data penduduk desa dan mempermudah dalam melayani warga desa yang mengajukan suratsurat.

2. Dapat membantu mempermudah dalam proses kegiatan pelayanan permohonan surat-surat kependudukan ditingkat desa

3. Dapat meningkatkan kualitas pelayanan aparat desa bagi masyarakat.

\section{B. Pembahasan}

1. Tampilan Halaman Utama

Pada tampilah Halaman Utama terdapat menu Home berisikan halaman selamat datang, menu Login berisikan input data penduduk, input surat, keluar, input surat masuk. Adapun tampila Halaman Utama dapat dilihat pada Gambar 7.

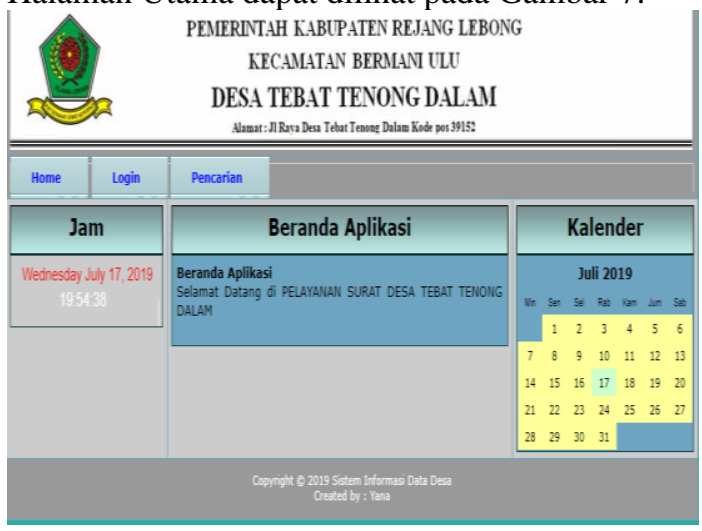

Gbr 7. Tampilan Halaman Utama

\section{Tampilan Login}

Tampilan Login merupakan system keamanan standar dalam aplikasi ini untuk melakukan input data, adapun tampilan Login dapat dilihat pada Gambar 8.

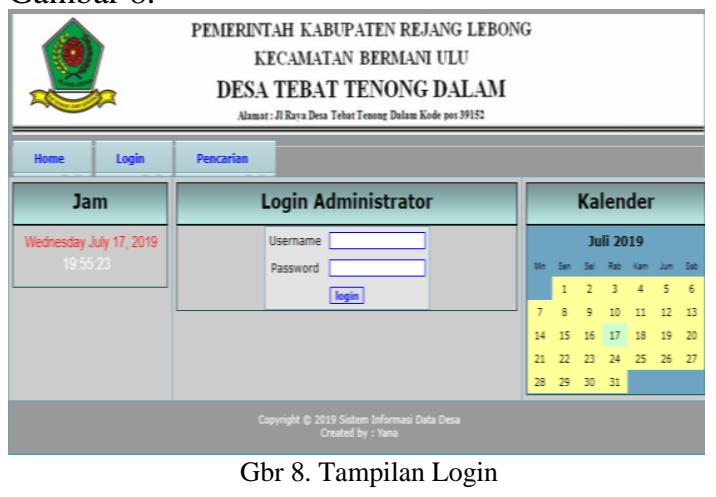

3. Dashboard Admin

Pada tampilan dashboard admin merupakan tampilan menu input data penduduk, input surat keluar, input surat masuk dalam aplikasi ini, adapun tampilan dashboard dapat dilihat pada Gambar 9.

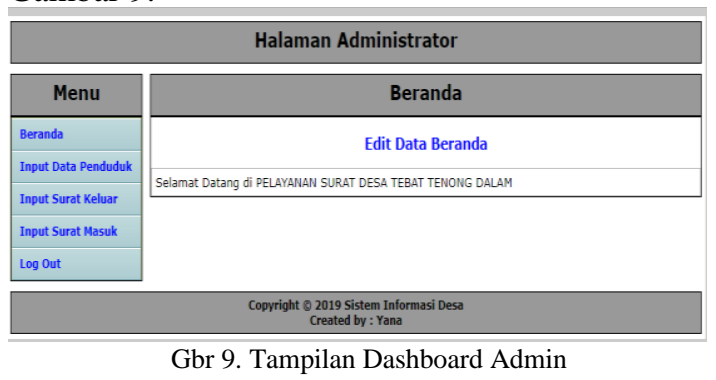

4. Input Data Penduduk

Pada halaman data penduduk menampilkan data penduduk dan tambah data penduduk. Serta terdapat pilihan edit jika ingin mengubah data penduduk dan pilihan hapus untuk menghapus data penduduk, adapun tampilannya dapat dilihat pada gambar 10.

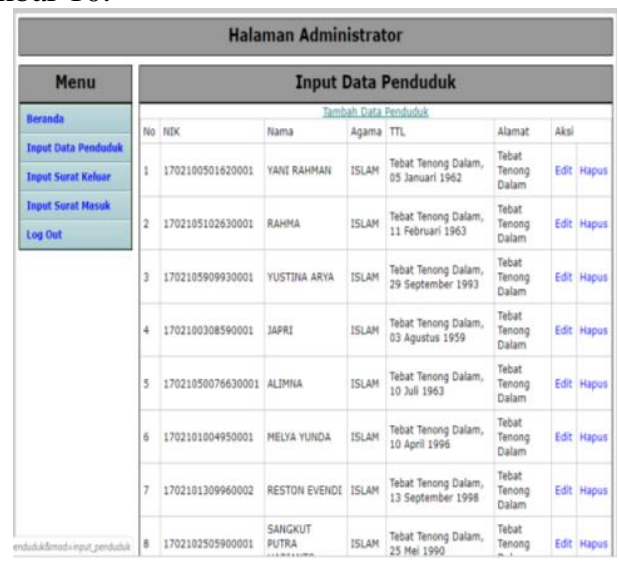

Gbr 10. Tampilan Input Data Penduduk

5. Tambah Data Penduduk

Tampilan tambah data penduduk merupakan pilihan untuk menambah data penduduk baru, adapun tampilan tambah data penduduk dapat dilihat pada gambar 11 . 


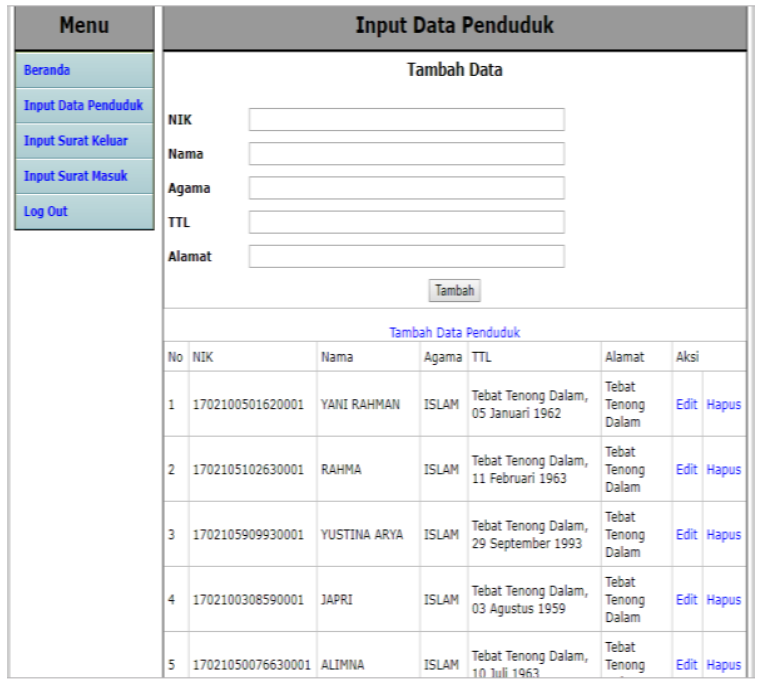

Gbr 11. Tampilan Tambah Data Penduduk

6. Input Surat Keluar

Tampilan input surat keluar merupakan rekapitulasi pencatatan surat keluar dalam aplikasi ini, adapun tampilan surat keluar dapat dilihat pada Gambar 12.

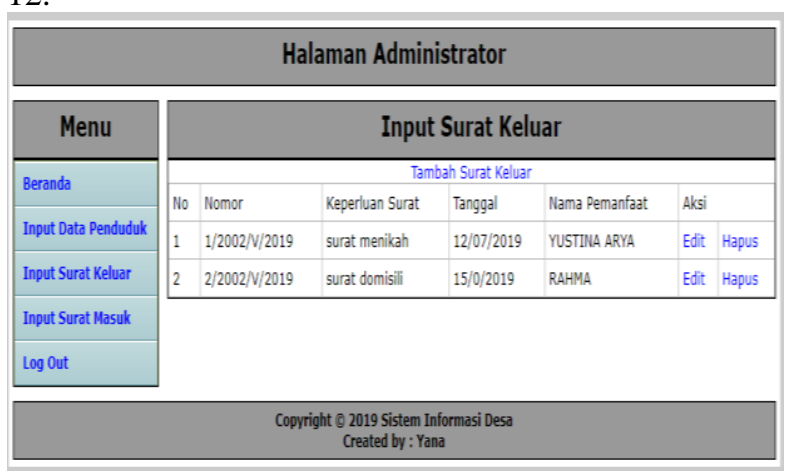

Gbr 12. Tampilan Input Surat Keluar

7. Input Surat Masuk

Tampilan input surat masuk merupakan rekapitulasi pencatatan surat masuk dalam aplikasi ini, adapun tampilan surat masuk dapat dilihat pada Gambar 13.

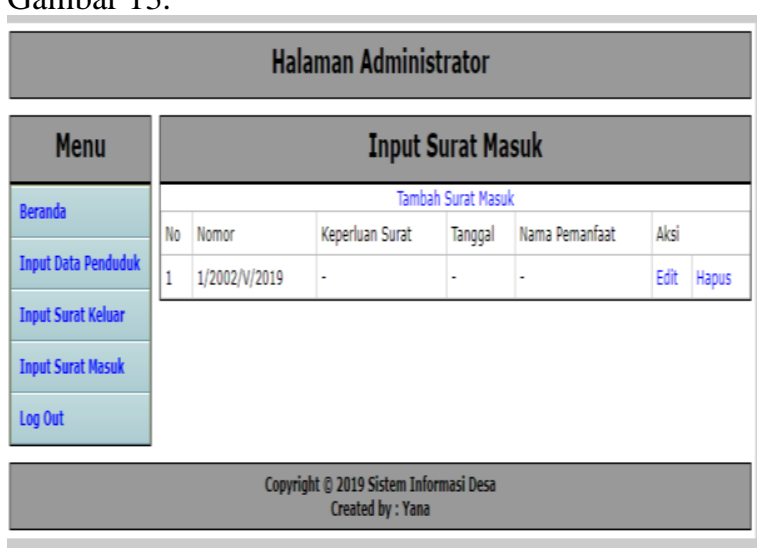

Gbr 13. Tampilan Input Surat Masuk

8. Halaman Pilih Surat Keterangan

Setelah halaman pencarian NIK akan tampilan data penduduk yang dicari berdasarkan NIK, serta menampilkan surat keterangan yang diperlukan, adapun tampilan pilihan surat keterangan dapat dilihat pada Gambar 14.
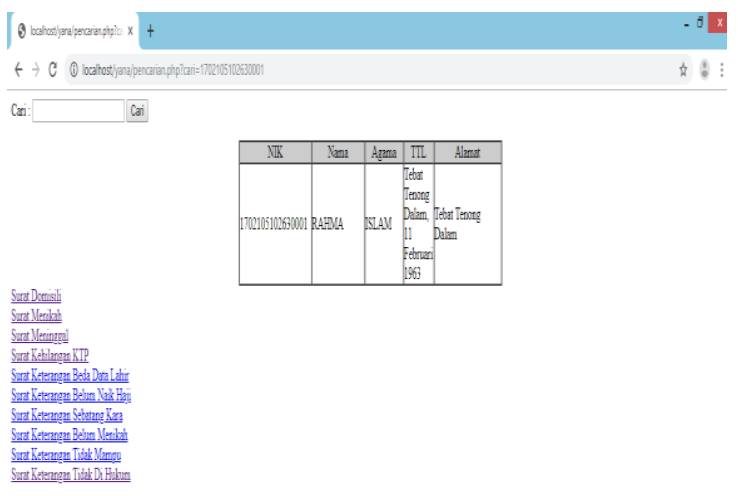

Gbr 14. Tampilan Halaman Pilih Surat Keterangan

\section{Tampilan Pencarian NIK}

Pada tampilan pencarian NIK digunakan untuk memilih data penduduk yang ingin memohon surat keterangan, adapun tampilan pencarian NIK dapat dilihat pada Gambar 15.

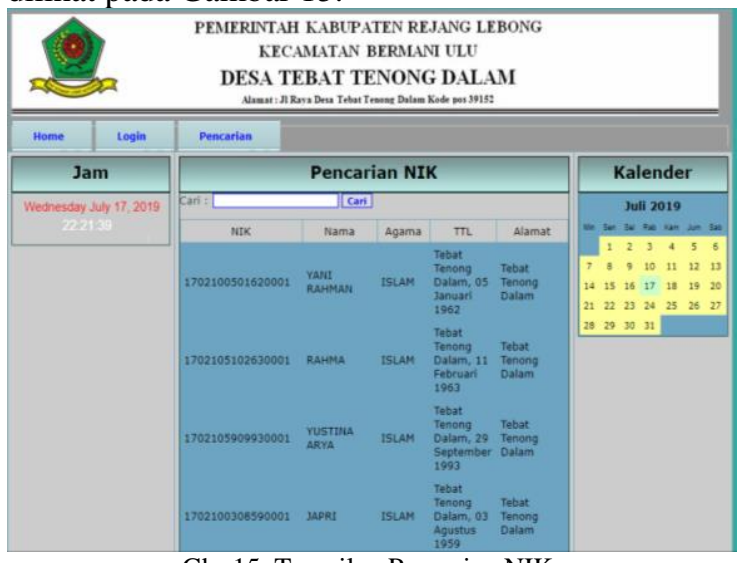

Gbr 15. Tampilan Pencarian NIK

10. Surat Keterangan

Pada tampilan surat keterangan domisili merupakan informasi warga pemohon surat keterangan domisili yang dikeluarkan dari kantor desa, adapun tampilan surat keterangan domisli dapat dilihat pada Gambar 16.

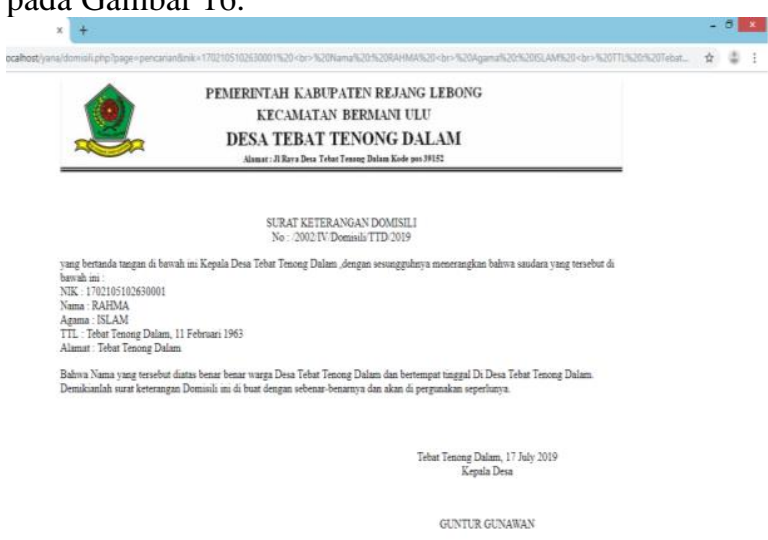

Gbr 16. Tampilan Surat Keterangan

115 |http://www.jurnal.umb.ac.id/index.php/JTIS 


\section{Penutup}

1. Kesimpulan

Kesimpulan yang dapat ditarik dari Aplikasi

Pelayanan Surat, adalah sebagai berikut :

a. Dapat membantu mempermudah dalam proses kegiatan pelayanan permohonan surat-surat kependudukan ditingkat desa

b. Untuk memperlancar pengumpulan data penduduk desa dan mempermudah dalam melayani warga desa yang mengajukan suratsurat

c. Berdasarkan pengujian black box testing setiap kriteria pengujian sesuai dengan hasil yang diharapkan.

d. Dapat meningkatkan kualitas pelayanan aparat desa bagi masyarakat.

2. Saran

Dari kesimpulan diatas, ada beberapa saran agar dapat menggunakan program aplikasi ini dengan maksimal.

1. Diharapkan pengembangan aplikasi ini dapat menjadi referensi bukan hanya untuk sistem perangkat desa melainkan juga untuk semua kalangan sebagai perkembangan informasi teknologi.

2. Diharapkan aplikasi ini selalu up to date sehingga aplikasi ini mengikuti perkembangan teknologi informasi berbasis smartphone.

Referensi

[1] Ariyadi, B. M., \& Bahar, B. (2017). Model Aplikasi Sistem Pelayanan Terpadu Pada Kantor Kelurahan. JUTISI, 5(1).

[2] Ramadhani, S., Hermawanto, F., \& Mariani, A. (2018). Aplikasi Pelayanan Surat Menyurat Desa Tanah Putih Berbasis Web. JTII (Jurnal Teknologi Informasi Indonesia), 3(2), 54-54.

[3] Hakim S, Rachmad, dan Ir. Sutarto, Msi. 2009, Mastering JavaTMKonsep Pemrograman dan Penerapannya Untuk Membuat Software Aplikasi, PT. Elex Media Komputindo, Jakarta

[4] Winarna, T., Aknuranda, I., \& Saputra, M. (2018). Pengembangan Sistem Informasi Pelayanan Surat Keterangan Studi Kasus: Pemerintah Desa Legundi Kecamatan Karangjati Kabupaten Ngawi. Jurnal
Pengembangan Teknologi Informasi Dan Ilmu Komputer, 2(12), 6235-6243.

[5] Guntari, R., \& Setiawan, R. (2016). Rancang Bangun Aplikasi Pengelolaan Surat Di Desa Tanjung Kamuning. Jurnal Algoritma, 13(1).

[6] Herpendi.(2017). Sistem Informasi Desa Di Kecamatan Takisung. Jurnal Sains dan Teknologi, 3(2), 76-82. 